\title{
Aspectos quanto à proteção jurídica na fase pré-negocial (Comentários ao Recurso Especial no 1.367.955/SP)
}

\author{
Culpa in contrahendo: legal protection \\ (Comments on Recurso Especial no 1.367.955/SP)
}

\author{
DANIEL USTÁRROZ \\ GABRIEL NAJFELD STANTON ${ }^{b}$ \\ LUIZ FERNANDO DOERING ${ }^{\mathrm{C}}$
}

\section{RESUMO}

O artigo analisa a responsabilidade civil pré-negocial. Aborda a doutrina de Rudolf von Jhering sobre o tema. Apresenta um precedente do Superior Tribunal de Justiça, discutindo os critérios que guiam a resolução de casos, no atual momento histórico.

Palavras-chave: Responsabilidade Civil Pré-Negocial. Rudolf von Jhering. Superior Tribunal de Justiça.

\begin{abstract}
The paper assesses pre-contractual liability. Discusses Rudolf von Jhering doctrine about the topic. Presents a Superior Tribunal de Justiça precedent, which analyzes criterions that guide case resolutions in the present.

Keywords: Pre-Contractual Liability. Rudolf von Jhering. Superior Tribunal de Justiça.
\end{abstract}

\section{INTRODUÇÃO}

O presente artigo discute as características da responsabilidade civil dita pré-contratual no direito brasileiro.

Inicialmente, apresenta um precedente do Superior Tribunal de Justiça, oriundo da $3^{\text {a }}$ Turma, de lavra do Ministro Paulo de Tarso Vieira Sanseverino.

Após, rememora alguns dos principais trechos da clássica de Rudolf von Jhering (Culpa in Contrahendo) para, ato contínuo, enfrentar o regramento da responsabilidade pré-negocial no direito brasileiro.

Ao final, aponta a correção do acórdão na aplicação do direito à espécie.

\section{APRESENTAÇÃO DO ACÓRDÃO}

O acórdão a ser examinado no presente artigo foi proferido no julgamento do recurso especial no $1.367 .955 / \mathrm{SP}^{1}$, interposto por Companhia Brasileira de Distribuição em face de acórdão prolatado pelo Tribunal de Justiça do Estado de São Paulo em ação indenizatória promovida por Asti Promoções e Eventos Ltda. - Massa Falida.

Em primeiro grau, a demandante arguiu ter sido contratada pela requerida para organizar evento, obrigando-se a preparar a iluminação do local, o paisagismo, a cobertura e a comunicação visual, entre outros aspectos. Alegou, ainda, que chegou a firmar

\footnotetext{
a Professor Adjunto de Direito Civil na PUCRS. Doutor em Direito Civil pela UFRGS. E-mail: <ustarroz@terra.com.br>.

b Acadêmico de Direito na PUCRS. E-mail: <gabriel@stantons.com.br>.

c Acadêmico de Direito na PUCRS. E-mail: <mattedoering@gmail.com>.
} 
uma via do contrato, ao passo que requerida, a despeito de não ter assinado o instrumento, deu como certo o acordo e exigiu que os preparativos fossem iniciados. Diante disso, a autora formalizou contratos com terceiros para que ocorresse a prestação do serviço contratado, que, posteriormente, foi cancelado pela ré. Em razão disso, postulou indenização pelos danos causados e pelos lucros cessantes.

A demandada, ao seu turno, contestou o pedido, aduzindo que nunca pedira à autora que iniciasse a organização do evento. A execução do contrato, segundo a sua tese, apenas poderia ser iniciada após a sua regular formação, a qual, no caso concreto, inocorreu.

O magistrado singular julgou improcedentes os pedidos, porquanto entendeu que o relacionamento estabelecido entre as partes ficou restrito à elaboração de orçamentos e projetos. Assinalou que nem mesmo teria havido definição sobre o preço, de sorte que as partes estariam envolvidas apenas em uma fase de negociações preliminares, razão pela qual não haveria embasamento legal para sujeitar o demandado à responsabilização civil pelo ocorrido.

A autora manejou apelação, a qual foi provida pela Corte estadual, tendo sido acolhido o pleito indenizatório. Entenderam os Desembargadores da Trigésima Segunda Câmara de Direito Privado que, apesar da contradição da autora, porque em determinados trechos alegou ter ocorrido efetiva contratação de seus serviços e, em outros excertos, admitiu a inexistência de contratação, a maneira como as negociações foram estabelecidas, principalmente em razão dos e-mails trocados e da elaboração de minutas contratuais, "davam como certa a realização do evento e criaram uma induvidosa expectativa da contratação". Portanto, deveria ser deferida a indenização postulada.

Irresignada, a demandada interpôs recurso especial pelo art. 105, III, alínea a, Constituição Federal, sob o argumento de prestação jurisdicional insuficiente, sopesamento equivocado das provas, ausência de manifestação dos representantes legais das partes acerca da contratação, inexistência de ato ilícito e dos pressupostos da responsabilidade civil pré-contratual, bem como indevida fixação de juros moratórios. ${ }^{2}$

Distribuído para a relatoria do Ministro Paulo de Tarso Sanseverino, o foi parcialmente conhecido, e, nesta parte, lhe foi dado parcial provimento.

De início, o Ministro Relator destacou que não havia nulidade por omissão no acórdão recorrido, pois o Tribunal a quo o fundamentou suficientemente. Assinalou que o juiz não estaria obrigado a se manifestar a respeito de todas as teses e diplomas legais invocados pelas partes. Além disso, votou por não conhecer do recurso especial na parte referente à valoração da prova, porque significaria reexaminar o conjunto fático-probatório dos autos, inviável pela via do especial, pela incidência da Súmula $n^{\circ} 07$ do Superior Tribunal de Justiça.

No tocante ao ponto nevrálgico do processo - a responsabilidade civil pré-contratual - entendeu que a solução passaria pela aplicação do princípio da boa-fé objetiva. Para embasar o seu entendimento, o Ministro destacou que dito princípio foi consagrado no direito alemão, pelo $\S 242$ do Código Civil daquele país (BGB). Diferentemente do princípio da boa-fé subjetiva, que representa o pensamento da pessoa em estar agindo de acordo com o direito, o Relator assinalou que a

\section{boa-fé objetiva (Treuund Glauben) apresenta-se em particular, como um modelo ideal de conduta, que se exige de todos os integrantes da relação obrigacional (devedor e credor) na busca do correto inadimplemento da obrigação, que é a sua finalidade.}

Frisou o Ministro que o princípio fundamental do direito privado "exerce múltiplas funções, desde a fase anterior à formação do vínculo, passando por sua execução, até a fase posterior ao adimplemento da obrigação", ou seja, como o caso em liça trata justamente da responsabilidade civil pré-contratual, e sendo possível aplicar o princípio a uma fase anterior ao efetivo acordo entre as partes, a decisão da Corte de Origem, sob o ponto de vista abstrato, estaria correta.

$\mathrm{O}$ voto recorre à lição de Judith Martins-Costa, a qual pontua que

o processo obrigacional supõe duas fases, a do nascimento e desenvolvimento dos deveres e a do adimplemento, as quais, nas obrigações que se endereçam à transmissão da propriedade, perpassam, como visto, dois planos, e nas demais, um plano só, pois o adimplemento é realizado no plano do Direito Obrigacional. Estas fases são desenvolvidas no tempo como um processo, no sentido hegeliando do termo, polarizando por sua finalidade, que é o adimplemento, com satisfação das partes. A fase do nascimento dos deveres, por sua vez, nem sempre surge ex abrupto e nem termina sem deixar rastros, pois pode ser antecedida por tratativas e demais atos preparatórios (nos quais se alocam deveres jurídicos de proteção), e pode ser seguida por um período ainda marcado por deveres, pós-contratuais. O nascimento dos deveres pode derivar de uma série de atos e acontecimentos. O ato resultantes da autonomia privada, o ato injusto e culposo, a literal disposição de lei, sendo também reconhecida a força normativa dos usos, o "poder de 
cogência peculiar à sociedade', e ainda de 'outros fatores [que] passaram a influir poderosamente no nascimento e desenvolvimento do vínculo obrigacional, fatores estes decorrentes da cultura da imersão dos valores que os Códigos revelam no campo social e das transformações e modificações que produzem'. Entre esses outros fatores estão o hoje alargado conceito de dano indenizável e a valorização jurídica do 'contato social' decorrendo, ainda, da incidência de princípios e diretrizes constitucionais, de modo muito especial o princípio da dignidade da pessoa humana e a diretriz da solidariedade social ${ }^{3}$.

O voto valoriza a noção de "contato social". Dele já decorreriam deveres jurídicos, de sorte que a atenção do direito ocorre já em momento pretérito à conclusão do negócio jurídico, a qual muitas vezes nem chega a ocorrer. No caso em comento, as partes iniciaram as tratativas em dezembro de 2004 para realização de evento em junho 2005 , cujo orçamento ultrapassou o valor de R $\$ 1.000 .000,00$ (um milhão de reais). Durante as trocas de mensagens eletrônicas, o que ocorreu diversas vezes, a requerente fez visita técnica, redigiu memoriais e também, pelo que se extrai dos seus argumentos, contratou terceiros, o que lhe gerou despesas de $\mathrm{R} \$ 200.000,00$ (duzentos mil reais). Não obstante isso, o evento foi postergado e, após, cancelado pela demandada sem a formalização de contrato.

Valendo-se da análise feita pelo Tribunal de Justiça do Estado de São Paulo, o Relator concluiu que o comportamento das partes criou uma justa expectativa na autora que o contrato seria celebrado. Ademais, a "iminência do evento, justificaria o início da contratação de terreiros antes mesmo da formalização do contrato". Além disso, mesmo que o negócio jurídico não tenha sido concretizado, considerando que ele não nasce abruptamente, haveria, no mínimo, o dever de lealdade entre as partes e quem desrespeita este preceito não pode ser isentado da responsabilidade. Portanto, o "cancelamento da empresa varejista ofendeu o princípio da boa-fé objetiva, gerando uma responsabilidade pré-contratual".

Quanto aos demais aspectos, fez incidir a Súmula $\mathrm{n}^{\circ} 05$ do Superior Tribunal de Justiça e considerou inviável a análise de e-mails, postulados pela recorrente para demonstrar que a negociação ocorreu por atos de prepostos sem poder de gestão.

Ao fim, estabeleceu que o marco inicial dos juros moratórios seria a citação, na medida em que a responsabilidade civil pela quebra das tratativas é um ilícito contratual (o Código Civil disciplina o tema no art. $422^{4}$, no Título V, “Dos Contratos em Geral”), registrando a jurisprudência Superior Tribunal de Justiça, nesse sentido.

Como se observa, o tema de fundo é a responsabilidade pré-negocial, razão pela qual merece destaque breve rememoração da doutrina de Rudolf von Ihering.

\section{BREVE REMEMORAÇÃO DA TEORIA DA CULPA IN CONTRAHENDO EM RUDOLF VON JHERING}

É de Rudolf von Jheringo mérito por ter identificado, ainda no século XIX, que a proteção dos negociantes deve ocorrer antes do momento de celebração do contrato. A sua obra "Culpa in Contrahendo ou indenização em contratos nulos ou não chegados à perfeição", publicada em 1860, apresenta o problema e algumas alternativas de solução. O próprio autor anuncia o seu desejo de "introduzir um tema inteiramente novo"s. Contudo, a obra prima permaneceu por muitas décadas inacessível ao leitor português, na medida em que apenas na década de 2000, foi traduzida e publicada pela Editora Almedina ${ }^{6}$. O presente tópico destaca algumas de suas ideais originais.

Logo em sua parte inicial, Jhering demonstra a sua insatisfação em relação a teoria do erro, a qual, tal como aplicada no século XIX, não oferecia adequadas soluções para o direito, deixando sem proteção o declaratário. Ilustra o estado da arte, naquele momento histórico, o caso comprador que, ao se dirigir ao mercado e se confundir com os sinais, postulava a entrega de $100 \mathrm{~kg}$ 's de carne, ao invés de $\$ 100$ do produto. $\mathrm{Na}$ visão da doutrina da época, o contrato deveria ser tido como nulo, mediante a prova do lapso. É que, se uma pessoa quer comprar $100 \mathrm{~kg}$ e outra apenas vender R\$100, não há vontades que se encontram, logo não há contrato... O mesmo problema ocorria quando contratantes estrangeiros se equivocavam com a língua contratual, utilizando termos distintos dos desejados.

À luz desses casos, identificou Jhering uma "lacuna sensivel" que gerava injustiça e desconsolo: "a parte culpada sai livre, a inocente é vítima da culpa alheia"7. Estudando lições romanísticas, Jhering localiza a "actioemti" e extrai a seguinte proposição:

a conclusão do contrato não origina meramente uma vinculação ao cumprimento, mas antes também, em certas circunstâncias, quando este efeito está excluído por causa de um qualquer obstáculo jurídico, uma obrigação de indemnização; a expressão 'nulidade' do contrato designa, segundo a terminologia romana e actual, apenas a ausência daquele efeito, mas não a de todos e quaisquer efeitos $^{8}$. 
Com tais colocações, Jhering reputou possível extrair efeitos jurídicos de contratos putativos.

O professor atribui a culpa um papel fundamental em sua ação de indenização:

sem tal ponto de vista, esta aparece como uma determinação positiva que, mesmo sendo ditada pelas exigências da eqüidade, está completamente isolada; com esse ponto de vista, ela enquadrase numa lei geral da teoria do contrato, a de que qualquer parte tem de responder perante a outra pelo dano que lhe causou por sua culpa. Sem esse ponto de vista, é uma acção de indenização que não exige qualquer culpabilidade da outra parte; com esse ponto de vista, evita essa singularidade e obtém o carácter normal de uma qualquer acção de indemnização ${ }^{9}$.

Com a preferência pela responsabilização subjetiva, Jhering postula a coerência do sistema.

Em sua obra, a seguinte passagem é emblemática:

quem contrata, sai deste modo do círculo de deveres puramente negativo do tráfico extracontratual e entra no positivo da esfera contratual, sai do campo da mera culpa in faciendo para o da culpa in non faciendo, da diligentia positiva, e a primeira e mais geral obrigação que assim assume é a seguinte: aplicar a necessária diligentia logo no próprio contratar. Não são apenas as relações contratuais formadas, mas antes logo as que estão em formação que têm de estar sob a protecção das regras sobre a culpa, se não se quiser que o tráfico contratual seja neste aspecto obstaculizado de forma significativa, que cada contraente seja exposto ao perigo de se tornar vítima da negligência alheia ${ }^{10}$.

O conceito de "diligentia" contratual é o cerne da teoria de Jhering, que o próprio autor sintetiza na seguinte frase: "o imperativo da diligentia contratual vale, tal como para relações contratuais formadas, também para relações contratuais em formação, uma sua violação fundamenta aqui, como ali, a acção contratual de indemnização".

Outro mérito de Rudolf von Jhering, na obra analisada, é a consagração dos conceitos de interesse negativo e positivo, hoje aplicados na doutrina e jurisprudência brasileiras. Conforme a sua obra, o interesse do comprador poderia ser concebido de duas maneiras:

segundo uma delas, como o interesse na manutenção do contrato, ou seja, no cumprimento - aqui o comprador receberia num equivalente em dinheiro tudo aquilo que teria tido em caso de validade do contrato; diversamente, como um interesse na não conclusão do contrato - aqui receberia o que teria tido se a realidade exterior da conclusão do contrato não se tivesse de todo verificado. Alguns exemplos esclarecerão esta diferença que pretendo designar, por razões de síntese, como interesse contratual positivo e negativo ${ }^{11}$.

Para Jhering, o primeiro interesse estaria fundamentado na validade do contrato, ao passo que o segundo na sua invalidade. Salientou: "só na medida em que o contrato é válido pode o comprador exigir a sua execução, ou, o que é o mesmo, o seu interesse no cumprimento". Os lucros cessantes dependeriam da validade do contrato. Já a "perda positiva" poderia ser indenizada pelo insucesso da relação contratual inválida ${ }^{12}$.

Por tais fundamentos, na teoria de Jhering, a responsabilização pelo ilícito pré-negocial limita-se ao interesse negativo, na medida em que seria incoerente atribuir à vítima indenização pelos benefícios que o cumprimento de um contrato nulo ou inválido geraria.

Esse "despertar do direito" para a fase anterior à formação do contrato permitiu que, ao longo do século $\mathrm{XX}$, a sua teoria fosse aprimorada, sempre com o objetivo de equilibrar o vínculo obrigacional e proteger as legítimas expectativas das pessoas.

\section{ANÁLISE DA EVOLUÇÃO DAS IDEIAS DE JHERING NO BRASIL}

Como mencionado, após a elaboração teórica de Rudolf von Jhering, o Direito despertou para um problema grave: a proteção jurídica para as pessoas, antes mesmo da formação do contrato. ${ }^{13}$ A liberdade de contratar, a qual logicamente engloba a aferição da conveniência de contratações, permanece a regra. Contudo, situações excepcionais permitiriam a responsabilização civil por atos pré-contratuais, para proteger as expectativas legítimas das pessoas.

Como se sabe, a responsabilidade civil pré-negocial incide para regular situações anteriores à formação do contrato, no período comumente denominado de tratativas. Na aclimatação da teoria de Jhering, no Brasil, houve naturalmente algumas adaptações à luz de nossa cultura. Dentre os precursores nacionais, merece destaque a contribuição de Clóvis do Couto e Silva, com a compreensão complexa do vínculo obrigacional e a valorização do contato social. Segundo o autor, este conceito "[...] justifica o nascimento de direitos e obrigações, quando não existe contrato"14, ou seja, as ações ou omissões das partes durante o período que antecede a formação do contrato já permitiram 
- em situações excepcionais - a caracterização da responsabilidade civil.

Atenta-se que a noção de contato social é fluida. Há diversos graus de contato social. Uma de suas mais intensas manifestações é o contrato, pela incidência da autonomia privada. Outra, mais reduzida, é a responsabilidade aquiliana, guiada pelo destino. Entre esses polos, concorrem situações juridicamente relevantes, como as negociações preliminares ${ }^{15}$. Uma consequência corretamente aventada pela doutrina reside no fato de que, na aferição da responsabilidade civil pré-negocial, não se perquire violação de deveres principais (estes surgem com o contrato formado), mas sim os ditos deveres instrumentais, porquanto se formam em momento anterior à celebração do negócio jurídico ${ }^{16}$.

No que tange às negociações preliminares, ressaltase que elas podem ou não conduzir a um negócio jurídico, porque o iter contratual é extremamente dinâmico. A obrigação, portanto, é um processo composto por várias etapas interdependentes ${ }^{17}$. Quando exitosas as fases iniciais, conclui-se o contrato. Não há norma jurídica que imponha a contratação, porquanto nessa fase embrionária incide especialmente o princípio da autonomia privada, de sorte que as partes conservam liberdade para avaliar a conveniência da contratação, como regra.

Não obstante esta etapa seja sustentada pelo princípio da autonomia privada, é inegável que os demais princípios do ordenamento também aparecem. Um deles é a boa-fé objetiva, lembrada no voto do Ministro Sanseverino. Em que pese o art. 422 do Código Civil somente refira que a boa-fé deve ser observada na conclusão do contrato e na sua execução, na tradição brasileira, admite-se também a sua incidência nas fases pré e pós-contratual. A este respeito, Véra Jacob de Fradera refere que "já é exigido um comportamento pautado pela lealdade, pela confiança, logo, cooperativo" 18 .

No nosso direito, é justamente o art. 422, do Código Civil, que abriga a pretensão de reparação de danos na fase pré-contratual. Houve, portanto, uma objetivação da responsabilidade, se comparamos a abordagem de Rudolf von Jhering com o contexto atual. $\mathrm{O}$ paradigma da diligência contratual fundado na imputação subjetiva (culpa) da doutrina de Jhering, aparentemente, foi substituído pela aferição objetiva.

A boa-fé objetiva ${ }^{19}$, como descrito no voto do acórdão analisado, "apresenta-se em particular, como um modelo ideal de conduta, que se exige de todos os integrantes da relação obrigacional (devedor e credor) na busca do correto adimplemento da obrigação, que é a sua finalidade". Tradicionalmente, de sua aplicação, decorrem três consequências jurídicas: (a) a criação de deveres laterais; (b) a limitação do exercício jurídico e (c) auxílio na interpretação dos contratos. Em qualquer de suas concreções práticas, a finalidade será enriquecer o vínculo obrigacional, para proteger os próprios contratantes.

Como sublinhado pela doutrina, respeitar a boafé na fase pré-contratual não significa corresponder necessariamente às pretensões da outra parte, mas agir com lealdade, probidade e de maneira a não frustrar a confiança, quando despertada à luz de critérios jurídicos ("legítima expectativa"), decorrente de atos voluntários, do outro sujeito ${ }^{20}$.

No caso concreto, o acórdão reconheceu que as tratativas evoluíram ao longo de meses, com a permanente comunicação entre as partes, com o objetivo de garantir o sucesso do evento, o qual ocorreria proximamente. Conforme destacado no acórdão, as partes reuniram-se pela primeira vez em dezembro de 2004 para negociar acerca de evento que seria realizado em junho de 2005, e, neste lapso, se encontraram diversas vezes, tendo, inclusive, ocorrido troca de e-mails, visita técnica e elaboração de memoriais, tendo inclusive a recorrida iniciado a contratação com terceiros ${ }^{21}$, embora não oficializado o contrato. $^{22}$ Aplica-se, no ponto, a lição de Jorge Cesa Ferreira da Silva, "a conduta do sujeito que, antes do nascimento do vínculo (com as expressas declarações de vontade), rompe injustificadamente as negociações tão fortemente entabuladas com a outra parte ao ponto de gerar nesta, fundada expectativa na conclusão das negociações" 23 desrespeita estas diretrizes.

Nesse contexto, em que certo o prejuízo pela contratação de terceiros, o rompimento das negociações na iminência do evento foi tido como injustificado, o que ocasionou a condenação da ré a indenizar o dano emergente.

\section{CONCLUSÃO}

À luz do exposto, é possível concluir que o acórdão analisado acertou ao aplicar as premissas da responsabilidade civil pré-negocial ao caso concreto. Inicialmente, destacou que a regra, no período das tratativas é a liberdade das partes, as quais devem meditar em relação à conveniência da contratação. Entretanto, pela aplicação conjunta do princípio da boa fé objetiva, as expectativas, quando criadas ou estimuladas pelo comportamento da contraparte, merecem proteção jurídica.

No caso concreto, tendo em vista o avançado estágio das tratativas e a iminência do evento, cuja realização sempre fora desejada pela contratante, a 
desistência imotivada ofendeu a expectativa criada a partir da dinâmica daquela relação obrigacional específica. Aparentemente, o prejuízo gerado pelo cancelamento poderia ter sido evitado, caso a ré tivesse adotado maior cautela na proteção do patrimônio da outra parte, ao menos informando com antecedência acerca do risco do evento não ocorrer. Desta forma, o acórdão acertou ao aplicar o direito à espécie.

\section{REFERÊNCIAS}

BRASIL. Superior Tribunal de Justiça. RECURSO ESPECIAL. CIVIL E PROCESSUAL CIVIL. RESPONSABILIDADE CIVIL PRÉ-CONTRATUAL. NEGOCIAÇÕES PRELIMINARES. EXPECTATIVA LEGÍTIMA DE CONTRATAÇÃO. RUPTURA DE TRATATIVAS. VIOLAÇÃO AO PRINCÍPIO DA BOA-FÉ OBJETIVA. JUROS DE MORA. TERMO 'A QUO'. DATA DA CITAÇÃO. 1. Demanda indenizatória proposta por empresa de eventos contra empresa varejista em face do rompimento abrupto das tratativas para a realização de evento, que já estavam em fase avançada. 2. Inocorrência de maltrato ao art. 535 do CPC quando o acórdão recorrido, ainda que de forma sucinta, aprecia com clareza as questões essenciais ao julgamento da lide, não estando o magistrado obrigado a rebater, um a um, os argumentos deduzidos pelas partes. 3. Inviabilidade de se contrastar, no âmbito desta Corte, a conclusão do Tribunal de origem acerca da expectativa de contratação criada pela empresa varejista. Óbice da Súmula 7/STJ. 4. Aplicação do princípio da boa-fé objetiva na fase précontratual. Doutrina sobre o tema. 5. Responsabilidade civil por ruptura de tratativas verificada no caso concreto. 6 . Inviabilidade de se analisar, no âmbito desta Corte, estatutos ou contratos de trabalho, para se aferir a alegada inexistência de poder de gestão dos prepostos participaram das negociações preliminares. Óbice da Súmula 5/STJ. 7. Controvérsia doutrinária sobre a natureza da responsabilidade civil pré-contratual. 8. Incidência de juros de mora desde a citação (art. 405 do CC). 9. Manutenção da decisão de procedência do pedido indenizatório, alterandose apenas o termo inicial dos juros de mora. 10. RECURSO ESPECIAL PARCIALMENTE CONHECIDO E, NESSA PARTE, PARCIALMENTE PROVIDO. (REsp 1367955/SP, Rel. Ministro PAULO DE TARSO SANSEVERINO, TERCEIRA TURMA, julgado em 18/03/2014, DJe 24/03/2014)

COUTO E SILVA, Clóvis do. A obrigação como processo. São Paulo: J. Bushatsky, 1976.

FRADERA, Véra Jacob de. Dano Pré-Contratual: uma análise comparativa a partir de três sistemas jurídicos, o continental europeu, o latino-americano e o americano do norte. In: Revista de Informação Legislativa, ano 34, n. 136, out.-dez. 1997.

JHERING, Rudolf von. Culpa in contrahendo ou indenização em contratos nulos ou não chegados à perfeição. Coimbra: Almedina, 2008.

MARTINS-COSTA, Judith. A Boa-Fé no Direito Privado: sistema e tópica no processo obrigacional. 1. ed., $2^{\mathrm{a}}$ tir. São Paulo: Editora Revista dos Tribunais, 2000.

MARTINS-COSTA, Judith. Comentários ao novo Código Civil. Rio de Janeiro: Forense, 2003. Vol. V, tomo I: Do direito das obrigações, do adimplemento e da extinção das obrigações.

MARTINS-COSTA, Judith. Um Aspecto da Obrigação de Indenizar: notas para uma sistematização dos deveres pré-negociais de proteção no direito civil brasileiro. In: Revista dos Tribunais, São Paulo, v. 867, jan. 2008.

PELUSO, Cezar (Coord.). Código Civil comentado: doutrina e jurisprudência. 4. ed. Barueri: Manole, 2010.

SILVA, Jorge Cesa Ferreira da. A boa-fé e a violação positiva do contrato. Rio de Janeiro: Renovar, 2002.

\section{NOTAS}

${ }^{1}$ RECURSO ESPECIAL. CIVIL E PROCESSUAL CIVIL. RESPONSABILIDADE CIVIL PRÉ-CONTRATUAL. NEGOCIAÇÕES PRELIMINARES. EXPECTATIVA LEGÍTIMA DE CONTRATAÇÃO. RUPTURA DE TRATATIVAS. VIOLAÇÃO AO PRINCÍPIO DA BOAFÉ OBJETIVA. JUROS DE MORA. TERMO 'A QUO'. DATA DA CITAÇÃO. 1. Demanda indenizatória proposta por empresa de eventos contra empresa varejista em face do rompimento abrupto das tratativas para a realização de evento, que já estavam em fase avançada. 2. Inocorrência de maltrato ao art. 535 do $\mathrm{CPC}$ quando o acórdão recorrido, ainda que de forma sucinta, aprecia com clareza as questões essenciais ao julgamento da lide, não estando o magistrado obrigado a rebater, um a um, os argumentos deduzidos pelas partes. 3. Inviabilidade de se contrastar, no âmbito desta Corte, a conclusão do Tribunal de origem acerca da expectativa de contratação criada pela empresa varejista. Óbice da Súmula 7/STJ. 4. Aplicação do princípio da boa-fé objetiva na fase pré- contratual. Doutrina sobre o tema. 5. Responsabilidade civil por ruptura de tratativas verificada no caso concreto. 6. Inviabilidade de se analisar, no âmbito desta Corte, estatutos ou contratos de trabalho, para se aferir a alegada inexistência de poder de gestão dos prepostos participaram das negociações preliminares. Óbice da Súmula 5/STJ. 7. Controvérsia doutrinária sobre a natureza da responsabilidade civil pré-contratual. 8. Incidência de juros de mora desde a citação (art. 405 do CC). 9. Manutenção da decisão de procedência do pedido indenizatório, alterando-se apenas o termo inicial dos juros de mora. 10. RECURSO ESPECIAL PARCIALMENTE CONHECIDO E, NESSA PARTE, PARCIALMENTE PROVIDO. (REsp 1367955/SP, Rel. Ministro PAULO DE TARSO SANSEVERINO, TERCEIRA TURMA, julgado em 18/03/2014, DJe 24/03/2014)
2 Alegou especificamente violação aos artigos 333, I e 535, II, do Código de Processo Civil, e aos artigos 47. 166, IV; 186; 188, II; 405 e 844, do Código Civil.

3 MARTINS-COSTA, Judith. Comentários ao novo Código Civil. Rio de Janeiro: Forense, 2003, p. 51-53. Vol. V, tomo I: Do direito das obrigações, do adimplemento e da extinção das obrigações.

${ }^{4}$ Art. 422. Os contratantes são obrigados a guardar, assim na conclusão do contrato, como em sua execução, os princípios de probidade e boa-fé.

5 JHERING, Rudolf von. Culpa in contrahendo ou indenização em contratosnulos ou não chegados à perfeição. Coimbra: Almedina 2008, p. 01.

${ }^{6}$ Culpa in Contrahendo. Trad. Paulo da Mota Pinto. Coimbra, 2008.

7 JHERING, Rudolf von. Culpa in contrahendo ou indenização em contratosnulos ou não chegados à perfeição. Coimbra: Almedina 2008, p. 02 .

8 Ibid., p. 24

${ }^{9}$ Ibid., p. 31

${ }^{10}$ Ibid., p. 32

${ }^{11}$ Ibid., p. 13

12 Ibid., p. 17. A expressão "perda positiva" utilizada por Jhering nessa passagem equivale às despesas havidas para a formação do contrato.

${ }_{13}$ Décadas mais tarde, a doutrina, à luz das novas exigências sociais, apontaria outro problema análogo: a responsabilidade pós-contratual.

${ }^{14}$ COUTO E SILVA, Clóvis do. A obrigação como processo. São Paulo: J. Bushatsky, 1976, p. 89

15 MARTINS-COSTA, Judith. Um Aspecto da Obrigação de Indenizar: notas para uma sistematização dos deveres pré-negociais de proteção no direito civil brasileiro. In: Revista dos Tribunais, São Paulo, v. 867, p. 24 , jan. 2008. 
${ }^{16}$ MARTINS-COSTA, Judith. A Boa-Fé no Direito Privado: sistema e tópica no processo obrigacional. 1. ed., $2^{\underline{a}}$ tir. São Paulo: Editora Revista dos Tribunais, 2000, p. 487.

${ }_{17}$ COUTO E SILVA, op. cit. p. 10.

18 FRADERA, Véra Jacob de. Dano Pré-Contratual: uma análise comparativa a partir de três sistemas jurídicos, o continental europeu, o latinoamericano e o americano do norte. In: Revista de Informação Legislativa, ano 34, n. 136, p. 173, out.-dez. 1997.

${ }^{19}$ Interessante atentar que a boa-fé objetiva é inspirada no Direito alemão. "O dispositivo é a consagração do princípio da Treuund Galuben (lealdade \& confiança), radicado no $§ 242$ do $B G B$ (Código Civil Alemão) de 1900: 'o devedor está adstrito a realizar a prestação tal como exija a boa-fé, com consideração pelos costumes do tráfego"'. In: PELUSO, Cezar, (Coord.). Código Civil comentado: doutrina e jurisprudência. 4. ed. Barueri: Manole, 2010.

${ }^{20}$ MARTINS-COSTA, Judith. Um aspecto da obrigação de indenizar: notas para uma sistematização dos deveres pré-negociais de proteção no direito civil brasileiro. In: Revista dos Tribunais, São Paulo, v. 867, p. 26, jan. 2008.
${ }^{21}$ Consta na página 9 do acórdão, em trecho do voto do Ministro Relator Paulo de Tarso Sanseverino: "No caso concreto, consta no acórdão recorrido que a empresa de eventos (ora recorrida) e a empresa varejista (ora recorrente) iniciaram, em dezembro de 2004, tratativas para a realização do evento 'A Maior Loja de Informática do Brasil', programado para junho de 2005 e orçado em $\mathrm{R} \$ 1.075 .000,00$. As partes reuniram-se por diversas vezes e trocaram vários e-mails. A empresa de eventos realizou uma visita técnica, elaborou memoriais descritivos e, segundo alega, iniciou a contratação de terceiros, efetuando despesas da ordem de R $\$ 200.000,00 "$

${ }^{22}$ Página 9 do acórdão: "O Tribunal de Origem, soberano na análise das provas, considerou que o comportamento as $[$ sic $]$ partes, teria criado na empresa de eventos a 'induvidosa expectativa' (cf. fl. 491) de que o contrato viria a ser celebrado, fato que, aliado à iminência do evento, justificaria o início da contratação de terceiros antes mesmo da formalização do contrato".

${ }^{23}$ SILVA, Jorge Cesa Ferreira da. A boa-fé e a violação positiva do contrato. Rio de Janeiro: Renovar, 2002, p. 48. 